\title{
Understanding Agricultural Liability: Legal Risk Management Considerations
}

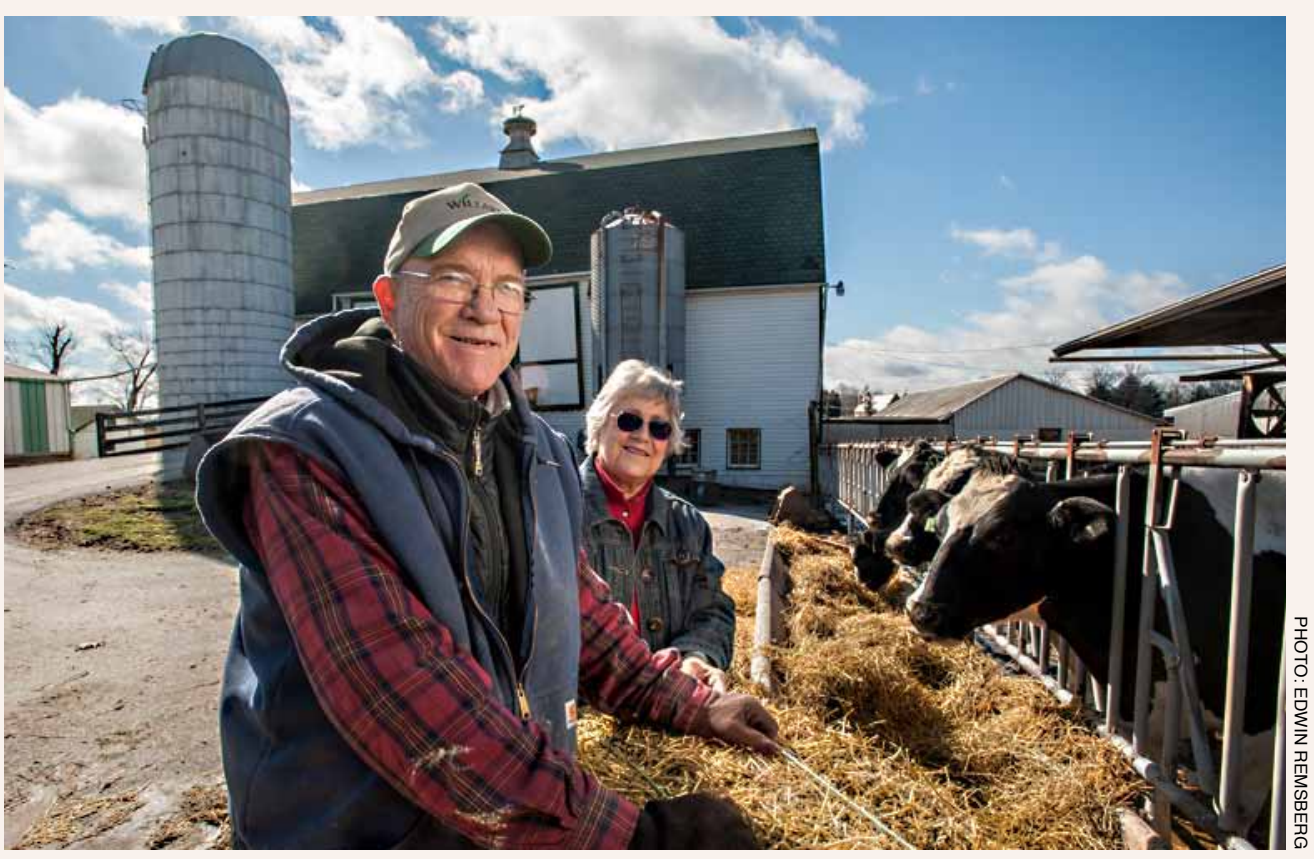

$\mathrm{T}$ he old adage, "the best defense is a good offense" certainly applies to farmers' concerns about possible nuisance or environmental claims. There are many proactive steps farm owners can take to prepare for lawsuits based on environmental or regulatory issues. A half day of expense for a skilled lawyer to review your operation, for example, could result in significant savings by avoiding litigation or enhancing the leverage to negotiate a settlement or prevail in the event of a lawsuit. Maintaining accurate, detailed records of all aspects of your farm operation will also help your defense. Because attorneys specialize in various aspects of agricultural law, research in advance to identify lawyers and their expertise will allow you to focus quickly on the appropriate individual to best develop your "good offense."
This fact sheet can serve as another tool in a farmer's risk management plans by providing information on how farmers can protect themselves from legal challenges from a nuisance or violation of an environmental permit. The information discussed in this fact sheet will not eliminate threats of lawsuits. Elimination of 100 percent of legal risk is not possible. However, there are tools available to help minimize the risks and costs associated with litigation. For example, purchasing insurance, such as comprehensive liability insurance, can help spread some of the risk to a third party (the insurance company). Following the suggestions in this report and the advice of a trusted attorney can help limit the risk of a potential lawsuit and build a successful defense if you are sued. 
"An Ounce of Prevention is Worth a Pound of Cure"

This fact sheet provides ways to implement an "ounce of prevention" by either outlining steps to prevent costly future litigation or developing the necessary records to demonstrate that your operation is in compliance with the law. These suggestions are meant to provide a starting point.

\section{Lawsuit Prevention}

A lot has been written in Maryland and other states on preventing lawsuits. University of Maryland Extension and Pennsylvania State University have series of fact sheets where farmers give their peers advice on getting along with neighbors, "educating" new neighbors who have never lived near a farm operation, and addressing other conflicts involving agricultural issues (Fuchs et al., $2007 \& 2007$ and Kelsey et al., 1997, 1997, \& 2008).

Professor Neil Hamilton discusses strategies for being a good neighbor in Chapter 5 of A Livestock Producer's Legal Guide To: Nuisance, Land Use Control and Environmental Law (Hamilton, 1992). Dr. Ritz, a poultry scientist with the University of Georgia Cooperative Extension, has developed a guide to reducing conflicts between poultry farmers and their neighbors (Ritz, 2010). These authors discuss the importance of working with your neighbors as one way of avoiding potential litigation.

You may need to help educate some of your neighbors who may not be knowledgeable about agriculture or how a farm operates. Be prepared to answer their questions thoughtfully and provide them with useful information (such as University of Maryland Extension
Working with your neighbors is one way of avoiding

\section{potential litigation.}

fact sheets, publications from the Maryland Department of Agriculture, etc). Helping your neighbors understand how you operate your business and why you utilize certain practices may put many of them at ease.

Examples of ways to educate your neighbors about your agricultural operation include:

- Hosting neighbors for a potluck/ barbeque on your farm;

- Allowing them to walk around your operation (but keeping them out of areas that would be unsafe);

- Sending out news updates through social media (such as Twitter or Facebook) that keep neighbors up-to-date on the type and duration of your current activities;

- Letting neighbors know how long you expect to be spraying herbicides under ideal conditions and whether they should keep their pets or children indoors during the spraying;

- Holding a meeting to explain any proposed expansion of your operation to your neighbors, how it could potentially impact them, plans to lessen those effects, and listening to any thoughts they may have on the expansion.

These are just some suggestions on ways to work with your neighbors; you may have other thoughts. Working to be a good neighbor can help avoid potential lawsuits over misunderstandings.

\section{Prepare for Possible Lawsuits by Maintaining Accurate Records}

Good recordkeeping can be critical when refuting claims that your operation is a nuisance or in violation of required permits. Things to consider including in your records are:

- dates of fertilizer and other chemical application, the chemical used, application rates, and rationales for applications;

- pictures showing pest issues before applications of herbicides or pesticides;

- permit applications and copies;

- formal and informal communications with the permitting authorities; and

- copies of recent soil and water tests.

Maintaining all records in a central safe location, such as a fireproof safe, safety deposit box, and/or electronic files with backups will allow you and your attorney to quickly begin planning your defense if claims should arise. Your records should include date-stamped photos of your operation that show conditions before you took action. These photos can help justify your decisions with regard to issues such as weed or insect infestations. Take advantage of digital camera or cellphone technology and keep a visual record to support the paper or electronic record of activities on the farm.

It can be stressful to be involved in an ongoing lawsuit or enforcement action. Being diligent in your recordkeeping and having the records easily accessible to you and your attorney is one way to help alleviate some stress associated with the pending legal action. 


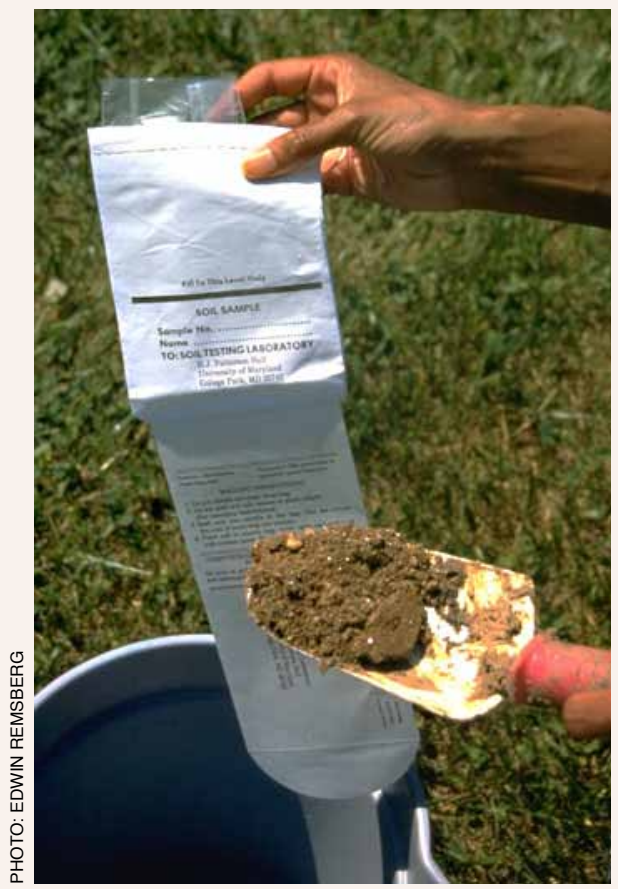

Good recordkeeping will help in refuting claims that your operation is a nuisance or in violation of required permits.
This fact sheet includes a worksheet to help you begin to develop a recordkeeping system (Appendix A). Use the worksheet to keep a record of when tillage operations and spraying occurred, as well as what you sprayed, the quantity per acre, and your reasons for taking the action.

For example, before you spray your corn with Roundup(C) to control weeds, you should document and photograph the weeds you observed, record the date you sprayed, and that you sprayed Roundup $($, noting the quantity per acre used. Because pesticide drift is sometimes a problem, you could also document the wind direction and speed on the day you sprayed.

\section{Follow the Requirements in Any Permit/Regulation/Statute}

Complying with permit, regulation and statute requirements related to your operation is a good defense to many claims. Using Maryland's Right-to-Farm law as a defense for a nuisance suit requires that an agricultural operation be in compliance with applicable federal, State, and local health, environmental, zoning, and permit requirements (Md. Code. Cts. \& Jud. Proc. § 5-403(c)). For more information see, Goeringer and Lynch, Understanding Agricultural Liability: Maryland's Right-to-Farm Law (2013).

Violating federal, State, and local environmental statutes, regulations, or permits is asking for trouble. Having good records can help prove you are in compliance with all environmental duties and provide you with a good defense to claims that you violated the law or your permits.

\section{Compile a List of Agricultural Attorneys to Contact in Case a Lawsuit is Filed}

It is important to remember that attorneys have areas of specialization and they may not be competent to handle all legal issues. If you are a poultry farmer, select an attorney competent to handle claims that you

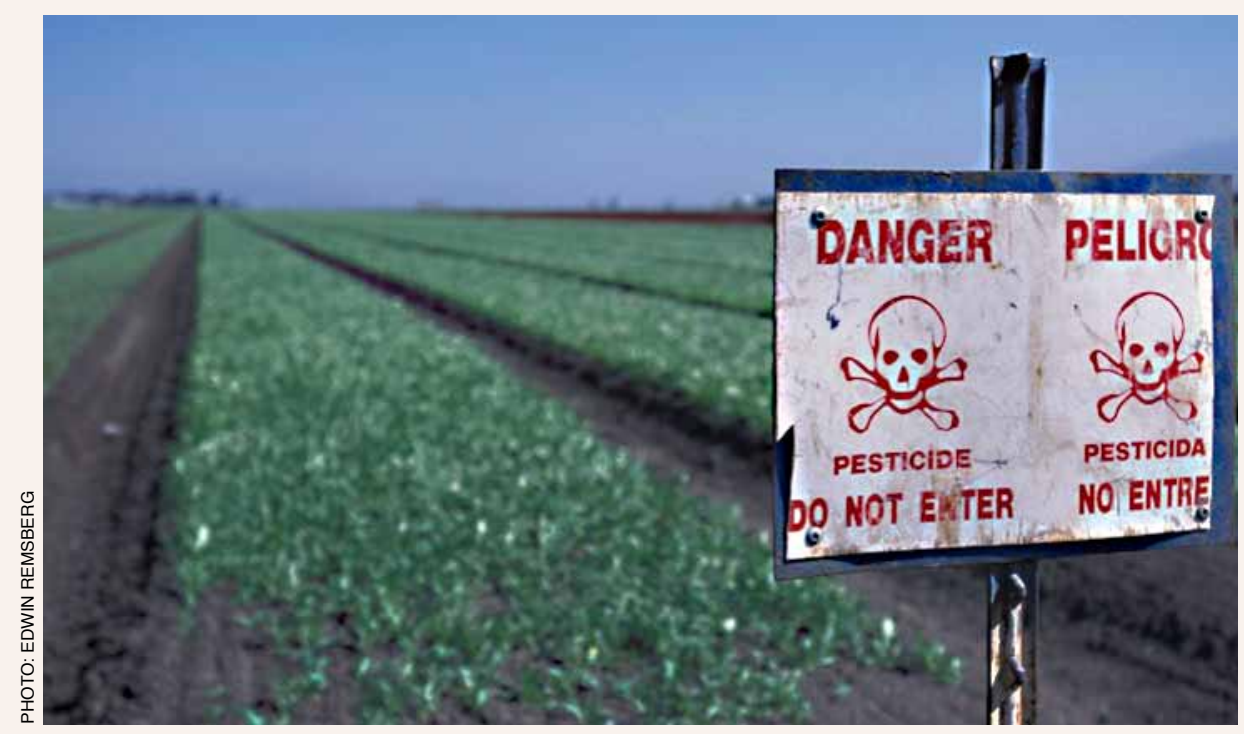

Because pesticide drift is sometimes a problem, you could also document the wind direction and speed on the day you sprayed. 


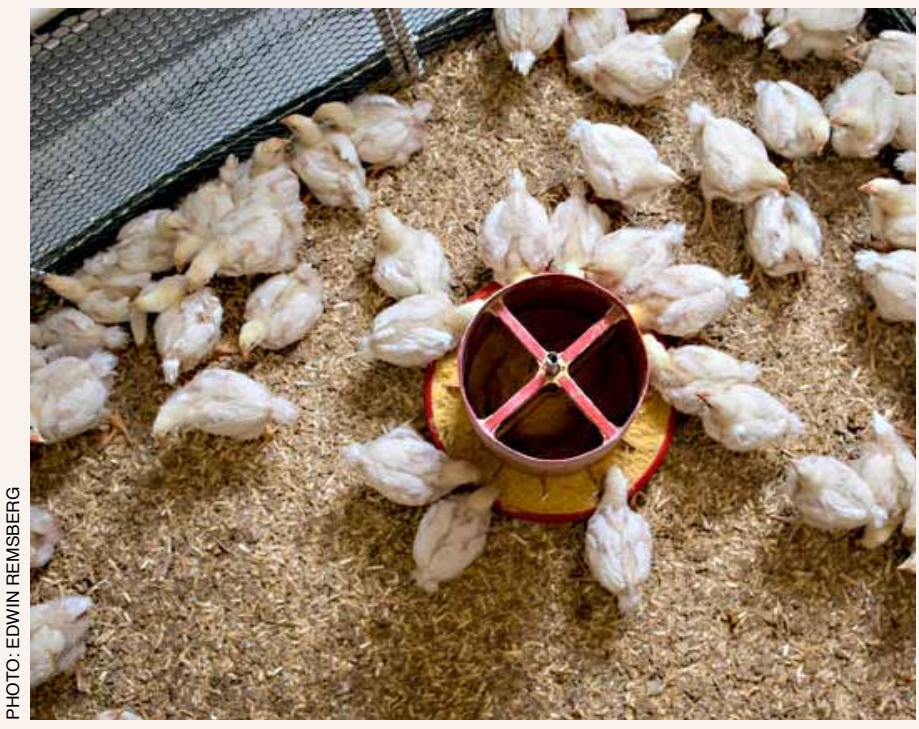

Using Maryland's Right-to-Farm law as a defense for a nuisance suit requires that an agricultural operation be in compliance with applicable federal, State, and local health, environmental, zoning, and permit requirements.

violated any required environmental permits. Similarly, if you have a row crop operation, your attorney should be able to handle claims that your operation is a nuisance due to dust or drift from chemicals you are spraying. The attorney should know the proper specialists to begin testing to prove your farm was not causing the damage at the outset of the legal action rather than researching experts as the lawsuit or claim progresses.

Once a lawsuit has been filed and you have been served notice, a clock begins for you to respond to the allegations. Researching attorneys who specialize in certain areas such as agricultural nuisance and environmental compliance in advance of any legal issues will enable you to select from a pool of potential attorneys. Having the advance information will save the initial steps of trying to locate potential lawyers when the clock is ticking for your response.

Just like other aspects of your farm operation, you can supervise your attorney's actions and cost by insisting on good communication, prompt billing, and the right to approve projects (though at the same time, it is important not to micromanage your case).
Once you have identified potential lawyers, meet with them and schedule

\section{a litigation audit or check-up.}

So how do you find attorneys who specialize in agriculture law? Pay attention to news accounts of agricultural lawsuits and note the lawyers representing the defendants. Ask other farmers if they know of attorneys who have experience with the issues you might be confronting. Contact the state or county bar association to ask about attorneys practicing in these areas. The American Agricultural Law Association, $\mathrm{http}$ //aglaw-assn.org/, is a national organization of attorneys specializing in different areas of agricultural law and may be a useful resource.

Once you have identified potential lawyers, meet with them and schedule a litigation audit or check-up. In many instances, working with a lawyer before a lawsuit or claim arises to identify areas of potential concern can help you avoid litigation. Your list of attorneys should be updated periodically so you have a current directory of legal specialists to contact if you are presented with a lawsuit. This can reduce some stress and allow you to quickly begin working with an attorney planning your defense.

\section{Liability Insurance Could Ease the Financial Burden of Lawsuit}

If, unlike most farmers, you do not currently have some form of liability insurance on your operation, consider purchasing it from a local agent experienced with insuring agricultural operations. Whether reviewing a potential policy or your current one, work with an agent to determine if a policy provides any coverage or a duty to defend a nuisance claim, environmental violation claim, or other possible claims. A policy that covers these types of claims could lessen some of your financial burden of having the necessary cash reserves to pay for an attorney. If the policy does not cover potential nuisance, environmental, or other claims, you may want to purchase a rider or an umbrella liability policy from your local insurance agent. 


\section{References}

Fuchs, Kurt, S. Dill, L. Lynch, \& J. Jones. Improving Neighbor Relations: Welcome to the Neighborhood. University of Maryland Extension, 2007.

Fuchs, Kurt, S. Dill, L. Lynch, \& J. Jones. Improve Neighbor Relations: Farmers Advise Farmers. University of Maryland Extension, 2007.

Goeringer, P. and L. Lynch, Understanding Agricultural Liability: Maryland's Right-to-Farm Law University of Maryland Fact Sheet, 2013.

Hamilton, Neil D. A Livestock Producer's Legal Guide to: Nuisance, Land Use Control, and Environmental Law. Des Moines: Drake Agricultural Law Center, 1992.

Kelsey, Timothy W., C.A. Abdalla. "Community Conflicts over Agriculture, Land Use, and Natural Resources." Finding Common Ground Series, Pennsylvania State University, 1997.

Kelsey, Timothy W., C.A. Abdalla. "Good Neighbor Relations: Advice and Tips from Farmers." Finding Common Ground Series, Pennsylvania State University, 2008.

Kelsey, Timothy W., C.A. Abdalla. "Understanding Your Community's Agriculture." Finding Common Ground Series, Pennsylvania State University, 1997.

Ritz, Casey W. Coexisting with Neighbors: A Poultry Farmer's Guide. University of Georgia Cooperative Extension, 2010.

Tunajek, Sandra. "Dealing with Litigation Stress Syndrome." AANA NewsBulletin, July, 2007, pp. 22-23.

\section{Reviewers:}

Paul would like to thank the following people for reviewing initial drafts and providing feedback:

Mae Johnson, Program Director, Maryland Agricultural Conflict Resolution Service, Maryland Department of Agriculture.

Kimberly A. Manuelides, Esq., Co-Chair Agriculture Law Section, Maryland State Bar Association.

Mark Powell, Chief Marketing Service, Maryland Department of Agriculture.

Susan A. Schneider, Director of the LL.M. Program in Agricultural and Food Law, University of Arkansas.

Brooke Schumm III, Daneker, McIntire, Schumm, Prince, Manning \& Widmann, PLC.

Margaret Witherup, Gordon-Feinblatt LLC. 


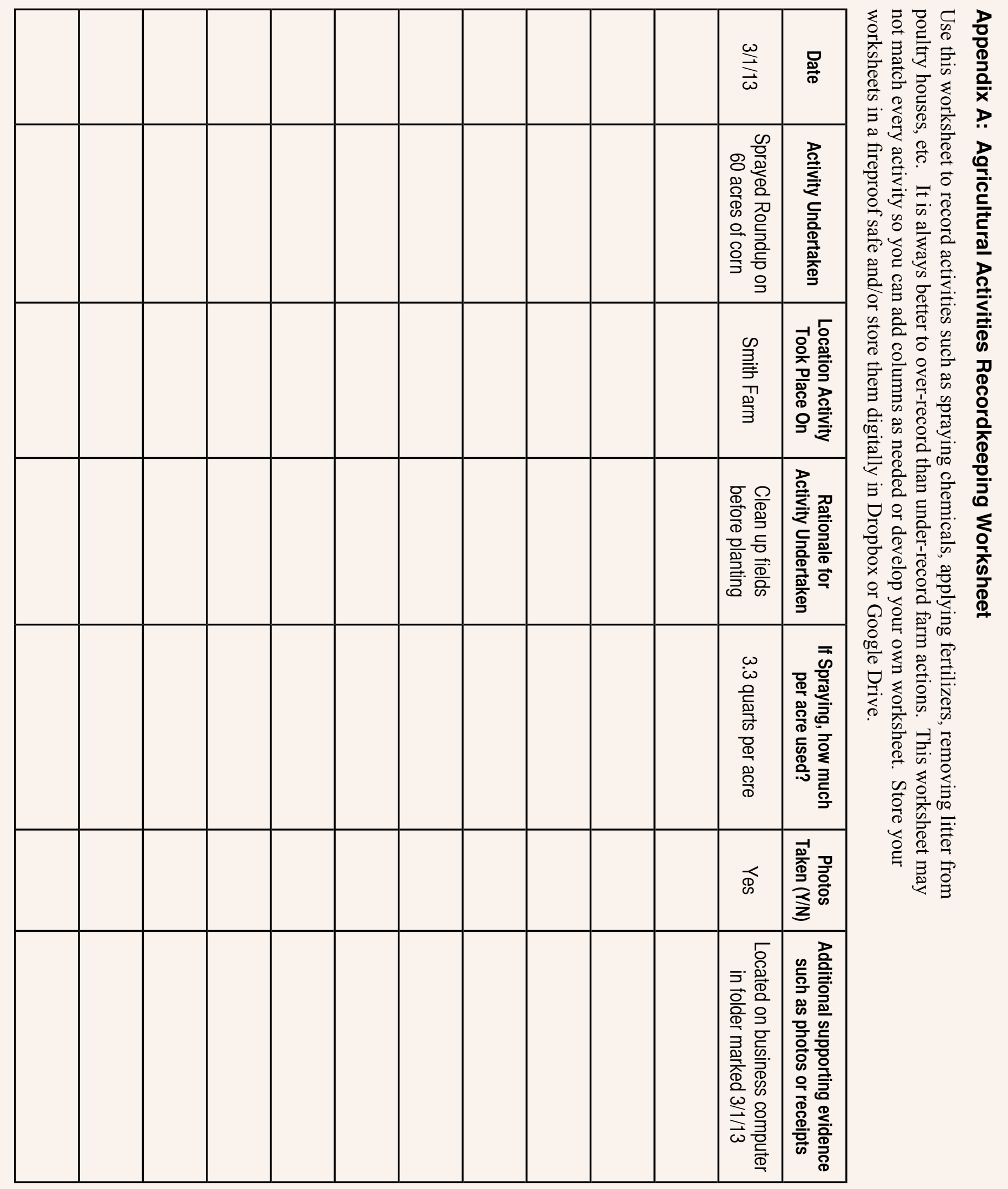


Note: This publication is intended to provide general information in understanding how to prepare for possible lawsuits and should not be construed as providing legal advice. It should not be cited or relied upon as legal authority. State laws vary and no attempt is made to discuss laws of states other than Maryland. For advice about how the issues discussed here might apply to your individual situation, you should consult an attorney.
Authored by:

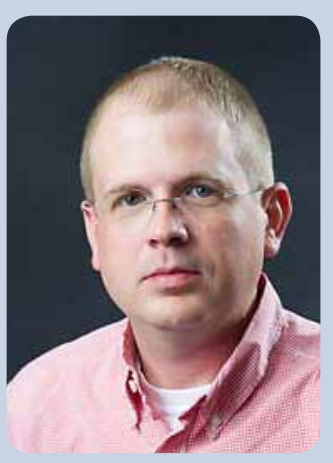

Paul Goeringer Extension Legal Specialist Igoering@umd.edu @aglawPaul

University of Maryland College of Agriculture and Natural Resources

Department of Agricultural and Resource Economics

Symons Hall, Room 2119 College Park, MD 20742

www.umaglaw.org

Twitter @MDAgLaw (301) 405-1293 